\title{
A Bibliometric Analysis and Visualisation of Research Trends in Corrosion of Orthopaedic Implants
}

\author{
Ana Sharma ${ }^{a}$ \\ Department of Biotechnology, Chandigarh University, Gharuan, Punjab,India. \\ 140413
}

Article History: Received: 11 January 2021; Accepted: 27 February 2021; Published online: 5 April 2021

\begin{abstract}
Several metals are used for orthopaedic implants. The bibliometric analysis had been conducted to understand the active authors, organizations, journals, and countries involved in the research domain of "corrosion of orthopaedic implants". All published articles related to "corrosion of orthopaedic implants" from "Scopus", were analyzed using the VOS viewer to develop analysis tables and visualization maps. This article had set the objective to consolidate the scientific literature regarding "corrosion of orthopaedic implants" and also to find out the trends related to the same. The most active journals in this research domain were Material Science and Engineering, Biomaterials and Acta Biomaterialia. The most active country was the United States of America. The leading organization engaged in research regarding corrosion of orthopaedic implants was the Chinese Academy of Sciences, China. The most active authors were Zhang X., Jacobs J.J. and Zhang Y.
\end{abstract}

Keywords: Orthopaedic-implants, Corrosion, Material engineering, Bibliometric analysis, VOS viewer,

\section{Introduction}

An engineered medical device to replace a missing or damaged joint or bone is known as an orthopaedic implant. Various types of orthopaedic implants and practices are widely used in the medical world. Orthopaedic implants are often subjected to wear and corrosion and ultimately lead to poor performance, pain, and wastage of money. Patient-specific orthopaedic implants are the trends of the day and can improve the performance and reduce the cost of implant (Haglin et al., 2016).

Corrosion is an important threat for orthopaedic implants (Cahoon, 1973)(Hallab and Jacobs, 2003)(Hallab, 2017)(Hallab, Urban and Jacobs, 2003)(Cohen, 1998)(Geringer, Forest and Combrade, 2005)(Kumar et al., 2010) Various types of surface treatments and surface coatings can be conducted on orthopaedic implants to improve their competency to be used as a material for orthopaedic-implants. Material engineering and surface engineering can play a significant role in the development of new types of orthopaedic implants; and in enhancing the performance of orthopaedic implants.

Sol-gel coating (Balestriere et al., 2020)(Ballarre et al., 2012)(Ballarre et al., 2013)(Ballarre and Ceré, 2018) Silver coating (Devasconcellos et al., 2012); Nanostructured Forsterite (Mg2SiO4) coating (Kheirkhah et al., 2015); Hydroxyapatite/hydroxyapatite-magnesium double-layer coatings (Rezaei et al., 2020)(Sutha et al., 2015); (Shibli and Jayalekshmi, 2008) are various surface coating procedures and surface modifications to improve performance of implants. Various types of mechanical, chemical and electrochemical surface preparation methods like electrolytic polishing and ultrasonic cleaning can resist the corrosion of steel implants and reduce the breakdown potential.

This bibliometric analysis will be a useful platform for future researchers by realizing the top researchers, organizations, and countries involved in research regarding corrosion of orthopaedic implants. This article is arranged into four sections. The first section is the introduction, followed by the discussion of the methodology by which the research was conducted. The third section deals with results and discussion. The fourth section deals with the conclusion. The following research objectives and research questions were framed for conducting bibliometric analysis systematically.

\subsection{Research Objectives}

a) To consolidate the literature regarding corrosion of orthopaedic implants

b) To find out the trends related to research in corrosion of orthopaedic implants

\subsection{Research Questions}

a) Who are the active researchers working on the corrosion of orthopaedic implants?

b) Which are the main organizations and countries working on corrosion of Orthopaedic implants?

c) Which are the main journals related to corrosion of orthopaedic implants?

\section{Research Methodology}

Scopus files had been used for this article. For the article selection, the Boolean used was TITLE-ABS (corrosion of orthopaedic implants) on 10/03/2021. All the tables in this paper were created by using Microsoft Excel and VOS Viewer. Grammarly was used for spelling and grammar checks. Mendeley was used for article review and citation. This paper had been inspired by bibliometric analysis in its presentation style, analysis, and methodology from the works (Farhat et al., 2013; Liao et al., 2016; Kolkailah et al., 2019; Rodríguez-Padial et al., 2019; Tran et al., 2019; Ullah et al., 2019; Shahid et al., 2020). 


\section{Results and discussion \\ 3.1 Results}

This first round of search produced an outcome of 1582 documents, in 14 languages, out of which 1512 documents were in English. The classification of document categories is shown in Figure 1. For improving the quality of the analysis, we had selected only the peer-reviewed articles and all other documents had not been considered. Thus after using filters "Article" and "English" the second round search produced an outcome of 1067 English articles (both open access and others). This paper had used all English articles to conduct bibliometric analysis and visualization using VOS Viewer. The English research articles in this domain since 1961 had been shown in Figure 2.

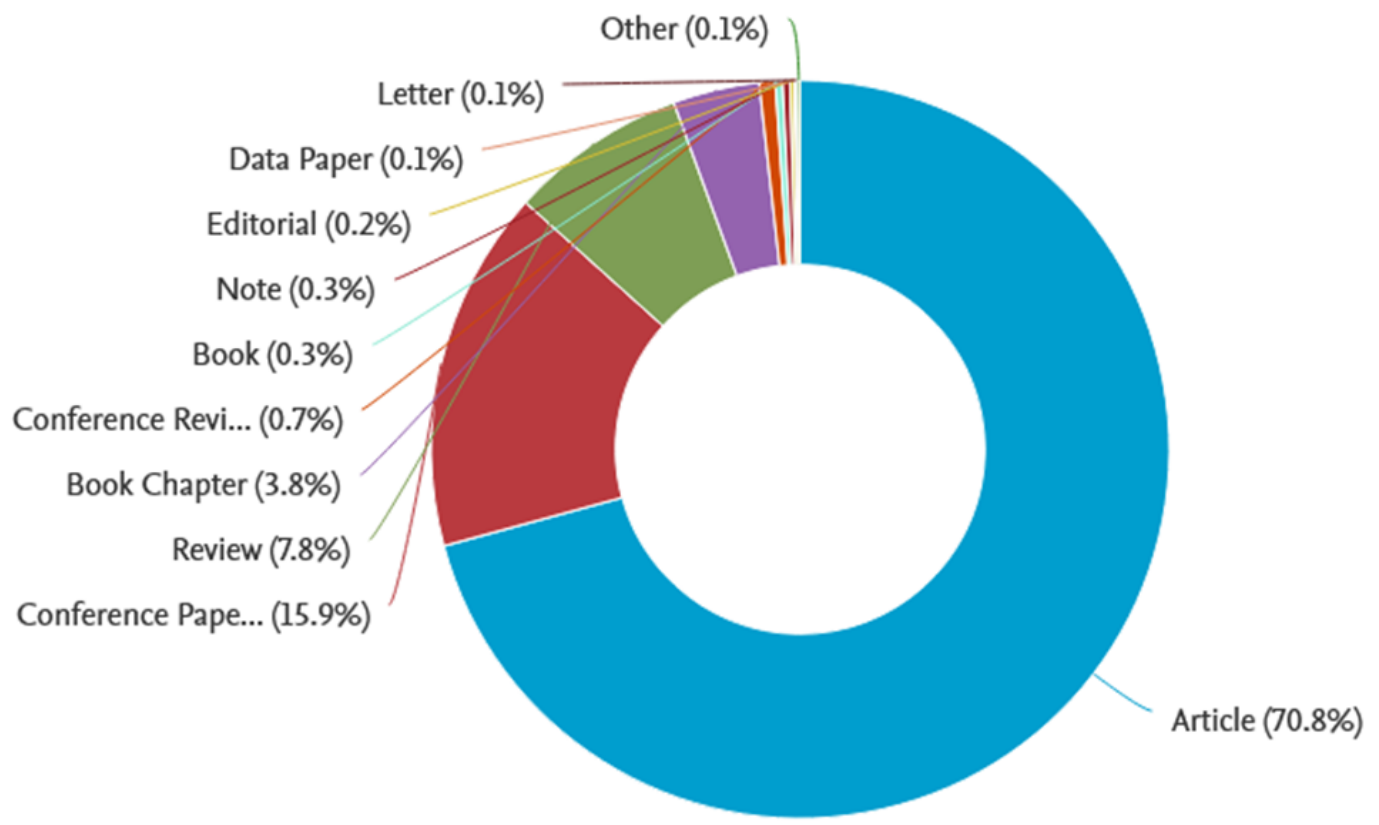

Figure 1: Classification of the documents on "Corrosion of orthopaedic implants", Source: www.scopus.com

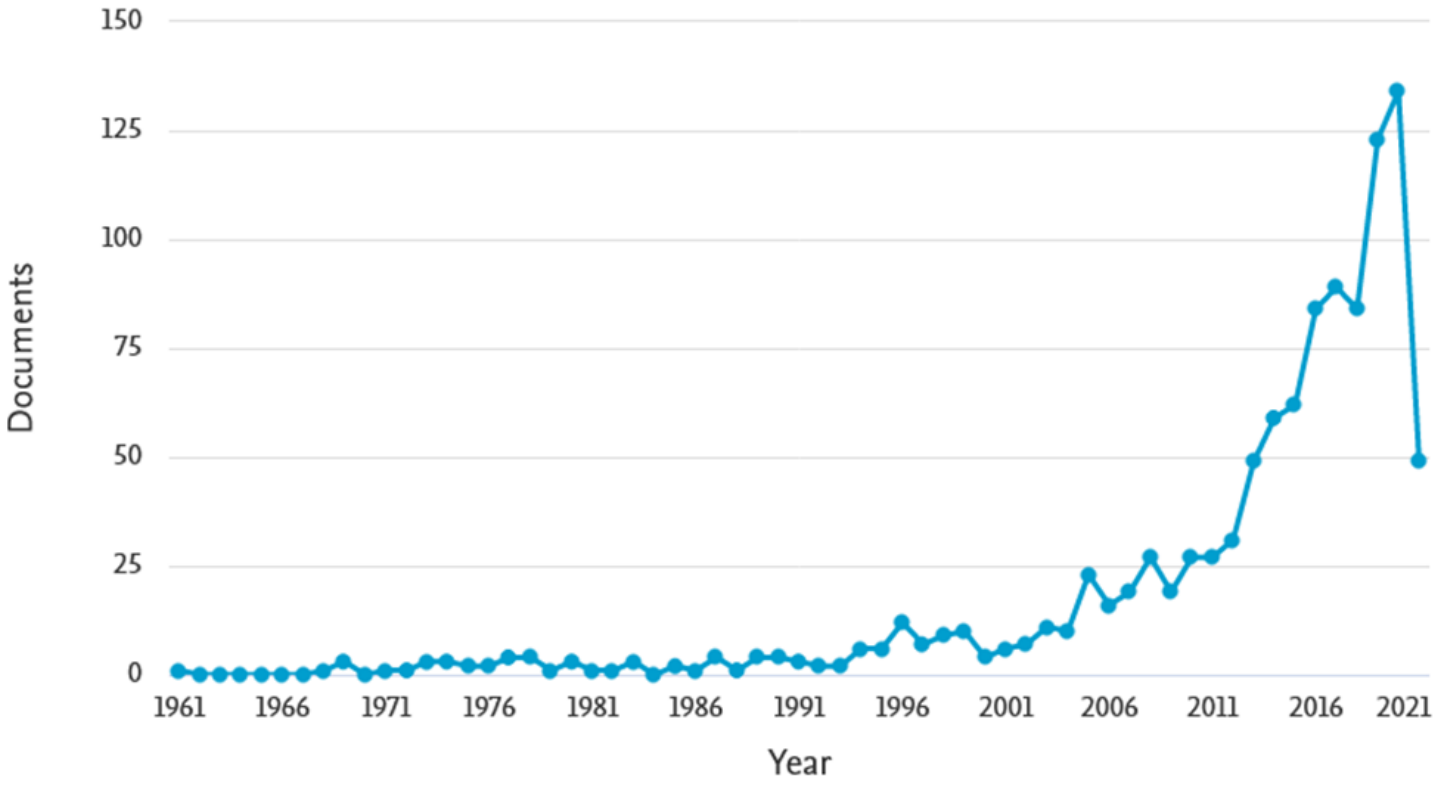

Figure 2: Period wise publication of articles, Source: WWW.scopus.com

Co-authorship analysis of top authors had been shown in figure 3. For a better presentation of the analysis, the parameters used were the minimum number of documents of an author as nine and the minimum number of citations of authors as one. This combination plotted the map of 32 authors, in 11 clusters. The overlay visualization map of co-authorship analysis plotted in Figure 3, points out the major researchers with their strong co-authorship linkages and clusters involved. 


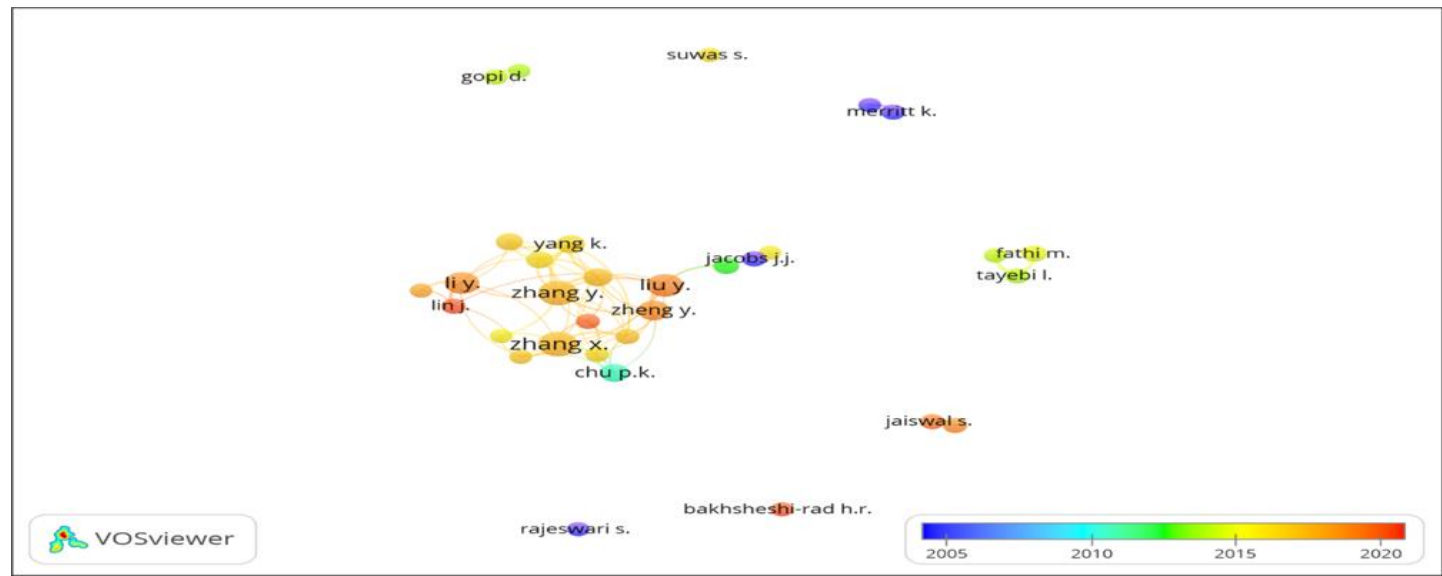

Figure 3: Co-authorship analysis on basis of authors

The citation analysis of top authors had been shown in table 1, along with co-authorship links. For the citation analysis, the parameters used were the minimum number of documents of an author as one and the minimum citations of an author as one.

Table 1: Highlights of most active authors

\begin{tabular}{|c|c|r|r|r|r|}
\hline Description & Authors & Documents & Citations & $\begin{array}{c}\text { Average } \\
\text { citations per } \\
\text { documents }\end{array}$ & $\begin{array}{c}\text { Link } \\
\text { strength }\end{array}$ \\
\hline $\begin{array}{c}\text { Authors with the } \\
\text { highest publication }\end{array}$ & Zhang X. & 26 & 1050 & 40.4 & 176 \\
\hline $\begin{array}{c}\text { Authors with the } \\
\text { highest co- } \\
\text { authorship links }\end{array}$ & Jacobs J.J & 14 & 1110 & 78.5 & 91 \\
\hline $\begin{array}{c}\text { Authors with the } \\
\text { highest citations }\end{array}$ & Zhang Y. & 25 & 471 & 18.8 & 189 \\
\hline
\end{tabular}

In Co-occurrence analysis, we had used all keyword analyses, by keeping the minimum number of occurrences of a keyword as 100. This combination plotted the map of 41 thresholds, in three clusters. The overlay visualization of co-occurrence analysis of keywords has been shown in Figure 4.

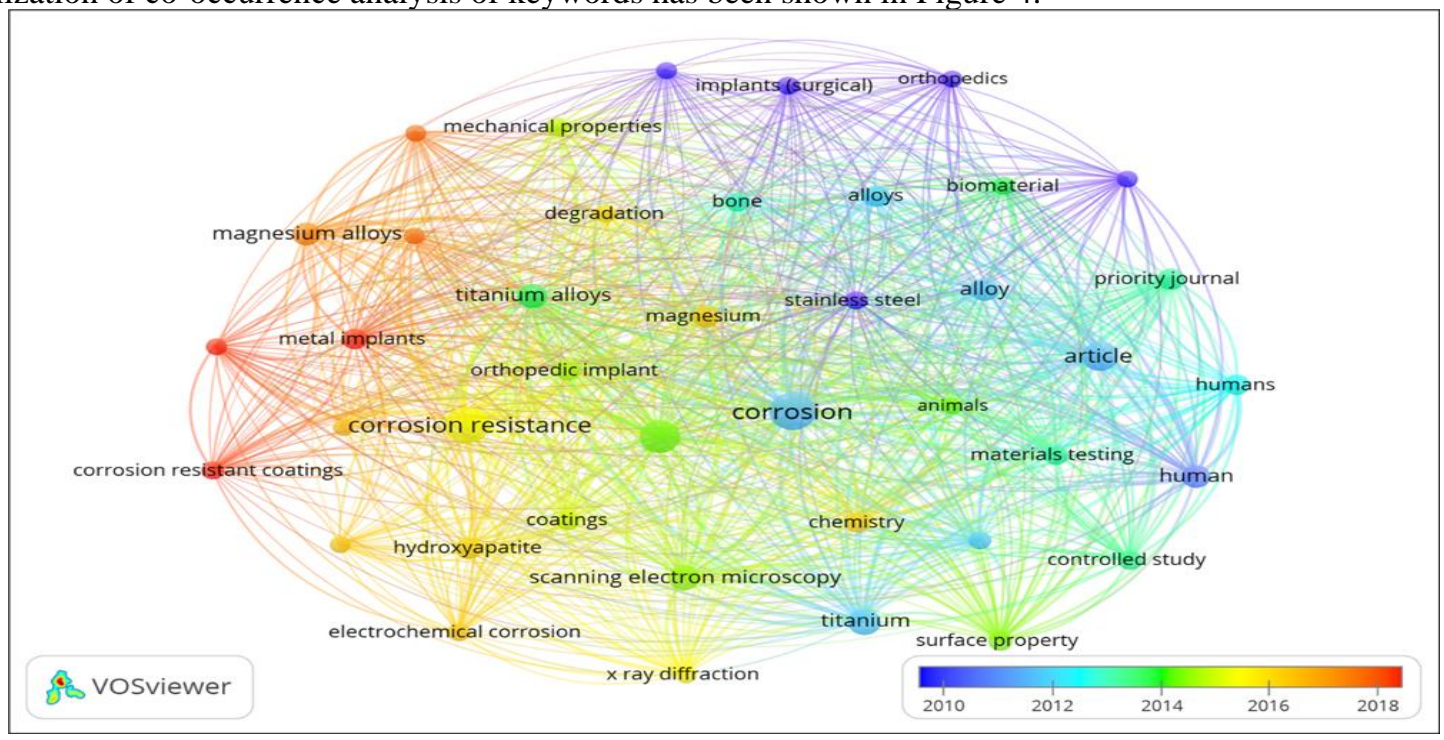

Figure 4: Co-occurrence analysis on basis of all keywords

The leading organizations engaged in research on "Corrosion of orthopaedic implants" had been found out by the volume of publications and citation analysis, the parameters used are the minimum number of documents of an organization as one and the minimum number of citations of organizations as one. The leading organization in the research regarding "Corrosion of orthopaedic implants", with the highest number of publications and citations, was the Chinese Academy of Sciences, China (Refer to table 2).

Table 2: Highlights of the most active organization 


\begin{tabular}{|l|c|c|c|c|}
\hline Organizations & Country & Document & Citatio & $\begin{array}{l}\text { Average } \\
\text { Citations } \\
\text { per } \\
\text { document }\end{array}$ \\
\hline Chinese Academy of Sciences & China & 43 & 1682 & 39.1 \\
\hline
\end{tabular}

Co-authorship analysis of the countries engaged in the research on "Corrosion of orthopaedic implants" had been shown in Figure 5. The overlay visualization map of co-authorship analysis plotted in Figure 5, points out the main countries with their strong co-authorship linkages and clusters involved.

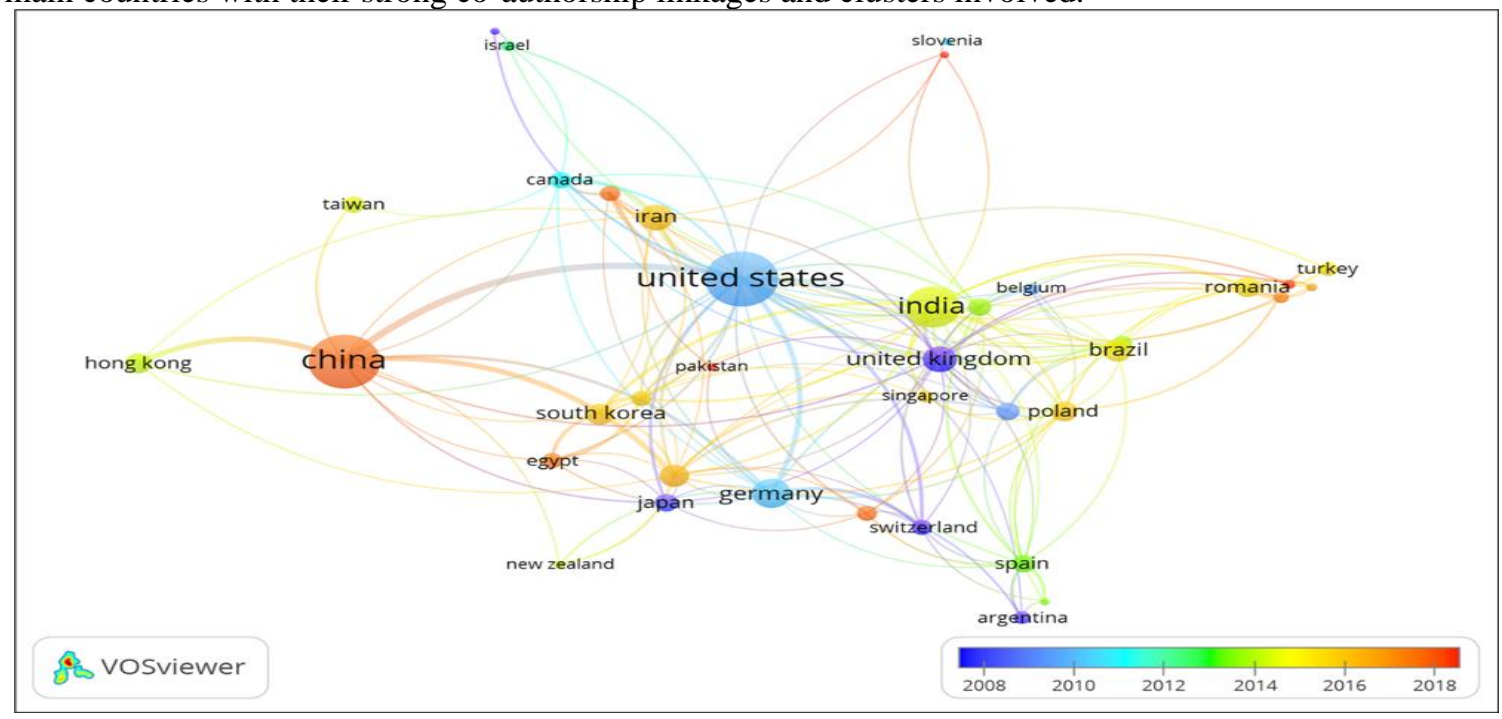

Figure 5: Co-authorship analysis on basis of countries

The citation analysis of top countries had been shown in table 3, along with co-authorship links. For the citation analysis, the parameters used were the minimum number of documents of a country as one and the minimum citations of the country as one.

Table 3: Highlights of Active Countries

\begin{tabular}{|c|c|c|c|c|}
\hline Description & Country & Document & Citation & Link strength \\
\hline $\begin{array}{l}\text { The country with the } \\
\text { highest publication, links, } \\
\text { and citations }\end{array}$ & $\begin{array}{c}\text { United States of } \\
\text { America }\end{array}$ & 231 & 7566 & 129 \\
\hline
\end{tabular}

The most active countries in this research domain were the United States of America with the highest number of publications, co-authorship links, and citations.

Link analysis and citation analysis were used to identify the most active journal in this research domain. We have taken the parameters of the minimum number of documents of a journal as one and the minimum number of citations of a journal as one for the link analysis and citation analysis. Highlights of the most active and relevant journals related to "Corrosion of orthopaedic implants" are shown in table 4 . Table 4 shows the journal activity of this research domain through parameters of publication volume, citations, and co-authorship linkages.

Table 4: Analysis of journal activity

\begin{tabular}{|c|c|r|r|r|r|}
\hline Description & Journal details & Documents & Citations & $\begin{array}{c}\text { Average } \\
\text { citations } \\
\text { per } \\
\text { documents }\end{array}$ & Links \\
\hline $\begin{array}{c}\text { Journal with the } \\
\text { highest publications }\end{array}$ & $\begin{array}{c}\text { Material } \\
\text { Science } \\
\text { Engineering }\end{array}$ & 55 & 1362 & 24.76 & 125 \\
\hline $\begin{array}{c}\text { Journal with the } \\
\text { highest citations }\end{array}$ & Biomaterials & 20 & 2748 & 137.4 & 114 \\
\hline $\begin{array}{c}\text { Journal with the } \\
\text { highest } \\
\text { authorship links co- }\end{array}$ & $\begin{array}{c}\text { Acta } \\
\text { Biomaterialia }\end{array}$ & 33 & 1813 & 54.93 & 139 \\
\hline
\end{tabular}

From the above discussion regarding the bibliometric patterns in the research regarding corrosion of orthopaedic implants, this research had observed a gradual increase in research interest regarding corrosion of 
orthopaedic implants from the starting of the millennium and the momentum is going on positively. This points out the relevance and potential of this research domain (Refer to Figure 2). The most active authors in this research domain were Zhang X., Jacobs J.J. and Zhang Y. with the highest publication, co-authorship links, and citations respectively (Refer to table 1). The overlay analysis of top countries researching dental implantations indicates that the United States of America was the leading country relating to the highest number of publications citations, co-authorship links (Refer to figure 5). The top journals of this research domain were identified as Material Science and Engineering with the highest number of publications; Biomaterials with citations; and Acta Biomaterialia links. From these wide sources of information, researchers can focus on top journals where they can identify the most relevant and highly cited articles regarding the corrosion of orthopaedic implants.

\section{Conclusion}

The corrosion of orthopaedic implants was an interesting research domain and the most active journals related to this research domain were Material Science and Engineering, Biomaterials and Acta Biomaterialia. The most active country was the United States of America. The leading organization engaged in research regarding corrosion of orthopaedic implants was the Chinese Academy of Sciences, China. The most active authors who had made valuable contributions related to dental implants were Zhang X., Jacobs J.J. and Zhang Y. This research domain offers a new avenue for researchers and future research can be on innovations in the corrosion of orthopaedic implants.

\section{References}

1. Balestriere, M. A. et al. (2020) 'Sol-gel coatings incorporating borosilicate bioactive glass enhance anticorrosive and surface performance of stainless steel implants', Journal of Electroanalytical Chemistry, 876. doi: 10.1016/j.jelechem.2020.114735.

2. Ballarre, J. and Ceré, S. M. (2018) Bioactive silica-based coating on stainless steel implants, Handbook of Sol-Gel Science and Technology: Processing, Characterization and Applications. Springer International Publishing. doi: 10.1007/978-3-319-32101-1_140.

3. Ballarre, J. et al. (2012) 'Enhancing low cost stainless steel implants: Bioactive silica-based sol-gel coatings with wollastonite particles', International Journal of Nano and Biomaterials, 4(1), pp. $33-53$. doi: 10.1504/IJNBM.2012.048216.

4. Ballarre, J. et al. (2013) 'Bone quality around bioactive silica-based coated stainless steel implants: Analysis by Micro-Raman, XRF and XAS techniques', Journal of Structural Biology, 184(2), pp. 164172. doi: 10.1016/j.jsb.2013.09.016.

5. Cahoon, J. R. (1973) 'On the corrosion products of orthopedic implants', Journal of Biomedical Materials Research, 7(4), pp. 375-383. doi: 10.1002/jbm.820070409.

6. Cohen, J. (1998) 'Current concepts review. Corrosion of metal orthopaedic implants.', The Journal of bone and joint surgery. American volume, 80(10), p. 1554. Available at: https://www.scopus.com/inward/record.uri?eid=2-s2.00032185679\&partnerID=40\&md5=8412ed7dd1c273e0419d52e2eb88dc2e.

7. Devasconcellos, P. et al. (2012) 'Antimicrobial particulate silver coatings on stainless steel implants for fracture management', Materials Science and Engineering C, 32(5), pp. 1112-1120. doi: 10.1016/j.msec.2012.02.020.

8. Farhat, T. et al. (2013) 'Research in congenital heart disease: A comparative bibliometric analysis between developing and developed countries', Pediatric Cardiology, 34(2), pp. 375-382. doi: 10.1007/s00246-012-0466-6.

9. Geringer, J., Forest, B. and Combrade, P. (2005) 'Fretting-corrosion of materials used as orthopaedic implants', Wear, 259(7-12), pp. 943-951. doi: 10.1016/j.wear.2004.11.027.

10. Haglin, J. M. et al. (2016) 'Patient-Specific Orthopaedic Implants.', Orthopaedic surgery, 8(4), pp. 417424. doi: $10.1111 /$ os.12282.

11. Hallab, N. J. (2017) 7.7 Fretting corrosion of orthopedic implants, Comprehensive Biomaterials II. Elsevier. doi: 10.1016/B978-0-12-803581-8.10176-6.

12. Hallab, N. J. and Jacobs, J. J. (2003) 'Orthopedic Implant Fretting Corrosion', Corrosion Reviews, 21(23), pp. 183-214. doi: 10.1515/CORRREV.2003.21.2-3.183.

13. Hallab, N. J., Urban, R. M. and Jacobs, J. J. (2003) Corrosion and biocompatibility of orthopedic implants, Biomaterials in Orthopedics. CRC Press. Available at: https://www.scopus.com/inward/record.uri?eid=2s2.0-77951170310\&partnerID=40\&md5=5b7da1afa0c56e9d8399f1d5cf8f9800.

14. Kheirkhah, M. et al. (2015) 'Surface modification of stainless steel implants using nanostructured forsterite (Mg2SiO4) coating for biomaterial applications', Surface and Coatings Technology, 276, pp. 580-586. doi: 10.1016/j.surfcoat.2015.06.012.

15. Kolkailah, A. A. et al. (2019) 'Bibliometric Analysis of the Top 100 Most Cited Articles in the First 50 Years of Heart Transplantation', American Journal of Cardiology, 123(1), pp. 175-186. doi: 10.1016/j.amjcard.2018.09.010.

16. Kumar, S. et al. (2010) 'Evaluation of fretting corrosion behaviour of CP-Ti for orthopaedic implant applications', Tribology International, 43(7), pp. 1245-1252. doi: 10.1016/j.triboint.2009.12.007. 
17. Liao, J. et al. (2016) 'The most cited articles in coronary heart disease: A bibliometric analysis between 1970 and 2015', International Journal of Cardiology, 222, pp. 1049-1052. doi: 10.1016/j.ijcard.2016.08.002.

18. Rezaei, A. et al. (2020) 'Hydroxyapatite/hydroxyapatite-magnesium double-layer coatings as potential candidates for surface modification of 316 LVM stainless steel implants', Ceramics International, 46(16), pp. 25374-25381. doi: 10.1016/j.ceramint.2020.07.005.

19. Rodríguez-Padial, L. et al. (2019) 'Trends and Bibliometric Impact of Research Grants of the Spanish Society of Cardiology/Spanish Heart Foundation (2007-2012) [Evolución e impacto bibliométrico de las becas de la Sociedad Española de Cardiología/Fundación Española del Corazón en el periodo', Revista Espanola de Cardiologia, 72(12), pp. 1012-1019. doi: 10.1016/j.recesp.2018.08.013.

20. Shahid, I. et al. (2020) 'Characteristics of highly cited articles in heart failure: A bibliometric analysis', Future Cardiology, 16(3), pp. 189-197. doi: 10.2217/fca-2019-0016.

21. Shibli, S. M. A. and Jayalekshmi, A. C. (2008) 'Development of phosphate interlayered hydroxyapatite coating for stainless steel implants', Applied Surface Science, 254(13), pp. 4103-4110. doi: 10.1016/j.apsusc.2007.12.051.

22. Sutha, S. et al. (2015) 'Mg-doped hydroxyapatite/chitosan composite coated 316L stainless steel implants for biomedical applications', Journal of Nanoscience and Nanotechnology, 15(6), pp. 4178-4187. doi: 10.1166/jnn.2015.9753.

23. Tran, B. X. et al. (2019) 'The current research landscape of the application of artificial intelligence in managing cerebrovascular and heart diseases: A bibliometric and content analysis', International Journal of Environmental Research and Public Health, 16(15). doi: 10.3390/ijerph16152699.

24. Ullah, S. et al. (2019) 'Publication trends of Pakistan Heart Journal: A bibliometric study', Library Philosophy and Practice, 2019. 